Psychology of Language and Communication 2018, Vol. 22, No. 1

\title{
Sciendo
}

DOI: $10.2478 /$ plc-2018-0019

\author{
ANETT WOLGAST ${ }^{1}$, YVONNE BARNES-HOLMES ${ }^{2}$, ULRIKE HARTMANN², \\ JASMIN DECRISTAN ${ }^{3}$ \\ ${ }^{1}$ Martin-Luther-University, Halle, Germany \\ ${ }^{2}$ Ghent University, Ghent, Belgium \\ ${ }^{3}$ Bergische Universität Wuppertal, Wuppertal, Germany
}

\section{INTERRELATIONS BETWEEN PERSPECTIVE TAKING AND READING EXPERIENCE: A LONGITUDINAL VIEW ON STUDENTS IN THE FIFTH YEAR OF SCHOOL}

\begin{abstract}
Social perspective taking (SPT) and the coordination of subjective and alternative perspectives are paramount to social behavior. Scholars tend to agree that approaches to conceptualizing SPT relate to interpersonal understanding and to language skills. The aim of this study was to determine whether interrelations exist between children's SPT and experience in reading because reading requires the reader to take various perspectives. Additionally, receptive vocabulary and reading fluency of 2,105 children were assessed and they completed a questionnaire at the beginning, in the middle, and at the end of fifth grade. Results indicated that the students' SPT was determined by gender and reading experience with books and newspapers. We conclude that this reading experience affects students' SPT levels positively; that finding can contribute to the development of school-based activities to enhance SPT levels.
\end{abstract}

Key words: reading, embodied cognition, social representations, developmental perspectives

\section{Introduction}

The concept of social perspective taking (SPT) encompasses seeing or imagining a situation from another person's perspective and tracking intentions, goals, values, or mental states through direct interactions, observations, or even reading (Baron-Cohen et al., 2015; Baron-Cohen,

Address for correspondence: Anett Wolgast, Department of Educational Psychology, Faculty of Education, Martin-Luther-University, Franckeplatz 1, 06110 Halle, Germany. E-mail: anett.wolgast@gmail.com 
Tager-Flusberg, \& Lombardo, 2013). In other words, SPT involves a mental representation of a social situation, combined with the ability to shift between subjective and alternative perspectives (Barnes-Holmes et al., 2004; Chambers \& Davis, 2012). In short, SPT involves seeing and participating in an alternative social perspective (Chambers \& Davis, 2012; Davlin, Rehfeldt, \& Lovett, 2011; Gehlbach, 2004; Selman, 1980). It is not surprising, therefore, that SPT facilitates effective social cooperation (Galinsky, Ku, \& Wang, 2005) and is paramount to the development of socially appropriate behavior.

\section{Components of SPT and Their Measurement}

Distinguishing between oneself and the perspective of others is likely to be an important feature of SPT. This ability is typically encapsulated within theory of mind, and is seen as integral to understanding and dealing cognitively with one's own intentions and behavior and those of others (e.g., Barnes-Holmes, McHugh, \& Barnes-Holmes, 2004; Baron-Cohen et al., 2013; Chambers \& Davis, 2012; Pelletier, 2006; Selman, 1980). In addition, a child must learn to appreciate when discrepancies occur between predicted behavior and behavior as actually observed, which often results from the attribution of false beliefs. The theory-of-mind approach relies heavily on the concept of false beliefs and its developmental importance to understanding the self and others (Baron-Cohen et al., 2013). According to Bloom and German (2000), false belief tasks assess specific situations or states, rather than dispositions or traits from previous appraisals and experiences.

Indeed, different methods have been used to explore the various components of SPT, such as seeing others (e.g., Epley \& Caruso, 2008; Gauvain \& Munroe, 2014), considering the mental states of others (e.g., Barnes-Holmes et al., 2004; Davis, 1980; Epley \& Caruso, 2008; Selman, 1980), and predicting and explaining the behavior of others (e.g., Baron-Cohen et al., 2013; Epley \& Caruso, 2008; Galinsky et al., 2005). Of these, perhaps the most basic skill involves simply seeing or imagining a person or fictional character, believed to require visual-spatial perspective taking (e.g., Gauvain \& Munroe, 2014; Piaget, 1977). Nonetheless, even this rather simple skill involves the ability to shift mentally from an internal (focus on oneself) to an external frame of reference (i.e., the mental representation of another). There is evidence that school-age children can do this, even when multiple alternative viewpoints are available (Blakemore \& Choudhury, 2006) and when the priorities of alternative perspectives must be accommodated (Foody, Barnes-Holmes, \& Barnes-Holmes, 2012). It is not surprising, therefore, that visual-spatial perspective taking has been associated with social perspective taking in children, adolescents (e.g., Blakemore \& Choudhury, 2006), and adults (e.g., Erle \& Topolinski, 2015). Such mental shifts highlight flexibilities in regarding oneself and others, and may be observed in creative arts, such as subjective mimicry (Epley \& Caruso, 2008; Sato \& Bergen, 2013; Smith 
\& Rose, 2011). One way in which a child may be able to simulate the social perspective of another is by applying retrospective or prospective social experiences and combining these with assumptions about that individual (e.g., Chambers \& Davis, 2012). Indeed, this can occur with great speed when the other person or the experience is similar to oneself (e.g., Chambers \& Davis, 2012).

More in keeping with the socio-moral tradition, Selman (1980) defined SPT as situated social competence (i.e., a state) and assessed it using dilemma tasks. From this approach, Selman argued that interpersonal understanding is generally operational by the age of 10 and involves applying the precise aspects of social competence that are necessary for a given situation. Thus, this social component of SPT suggests that levels of SPT likely interact in some way with broader social learning activities.

\section{The Dispositional Level View of Perspective Taking}

Of the different approaches that have been proposed, we concern ourselves here with the dispositional level view of perspective taking as a trait (Davis, 1980) and visual-spatial perspective taking as a state associated with this level (e.g., Erle \& Topolinski, 2015). However, standardized self-report tools often measure SPT as a trait in children, adolescents (e.g., Van der Graaff et al., 2014), and adults (e.g., the Interpersonal Reactivity Index; Davis, 1980). Using this type of measure, Van der Graaff et al. (2014) described inter-individual differences (with females generally superior to males) and developmental changes throughout adolescence, a pattern that is supportive of the dispositional level view of SPT.

Self-construal theory has been used to explain the apparent influence of cultural background on SPT and related cognitive abilities (Gardner, Gabriel, \& Lee, 1999; Varnum, Shi, Chen, Qiu, \& Han, 2014). Self-construal levels refer to the independent or interdependent self, also known as the cultural mindset. The levels vary cross-culturally (Gardner et al., 1999) and according to whether a level is accessible to a given individual (Varnum et al., 2014). In line with self-construal theory, Lillard (1998) highlighted the putative role of cultural sources of variation in simulating the perspective or situation of another person, in terms of visual-spatial perspective taking, theory of mind, and SPT. Specifically, she argued that because "children grow into different cultures with different practices (including linguistic ones), it might make sense that they form different ideas about the mind that fit those practices" (p. 5). In support of this view, Atkins, Uskul and Cooper (2016) found inter-individual differences in SPT using Davis' (1980) measure. That is, British participants reported higher levels of SPT than Asian university students. Hence, cultural background in childhood may be influential for SPT in adolescence and even adulthood. 


\section{The Relationship between SPT and Language}

An increasing number of research findings from different schools of thought in psychology support the relationship between SPT and language (e.g., Barnes-Holmes et al., 2004; Brunyé, Ditman, Mahoney, Augustyn, \& Taylor, 2009; Buhl, Möller, Oebser, Stein, \& Noack, 2009; Gauvain \& Munroe, 2014; Gore, Barnes-Holmes, \& Murphy, 2010; Lohmann \& Tomassello, 2003; Nieding \& Ohler, 1999; O'Brien \& Albrecht, 1992; Pelletier, 2006; Spinner, 1989). The reader is also referred to Milligan, Astington, and Dack (2007) for a meta-analysis that covers vocabulary or reading fluency. In general, the evidence shows that language-able children are better able to shift between different visual-spatial perspectives (e.g., Gore et al., 2010; O'Brien \& Albrecht, 1992) and social perspectives (e.g., Nieding \& Ohler, 1999) than their counterparts with language difficulties. Language-able children have also shown superiority on false belief tasks (e.g., Lohmann \& Tomasello, 2003; Pelletier, 2006) and relational tasks of perspective taking (Gore et al., 2010).

Theoretical approaches to identifying, both conceptually and empirically, the relationship between SPT and language include the relational frame theory (RFT). For RFT, many words commonly used in daily language and social exchange regard the perspectives that must be adopted by an individual in a given context, and these perspectives in turn endow words and utterances with meaning. For example, when a speaker says you, the listener always responds from the internal perspective $I$. This shifting between internal and external perspectives in RFT terms, as supported by research findings (Gauvain \& Munroe, 2014; Gore et al., 2010), was part of the basis of the current work.

\section{The Relationship between SPT and Reading}

Reading experience (RE) is defined as a growing network of knowledge constructed through reading habits, including frequent exposure to different types of text material, such as newspapers and fiction (see Cunningham \& Stanovich, 1997, for a brief overview). Thus, RE is associated with the reading context in which a reader forms a representation of meaning (Britt, Goldman, \& Rouet, 2012; Mullis, Martin, \& Sainsbury, 2015), which is, in turn, associated with the reader's existing network of vocabulary, related knowledge, strategies, and skills (e.g., Cunningham \& Stanovich, 1997; Schneider, 2015). Indeed, constructed meaning serves as a foundation for a reader's subsequent appraisals of textual material.

Receptive vocabulary and reading fluency are antecedents for the processing of information during reading and for understanding the behavior of fictional characters (e.g., Milligan et al., 2007). Indeed, reading would be impossible without a receptive vocabulary for textual material. Fluency is also necessary for abstracting the meaning of words and sentences, rather than 
simply seeing each letter or letter sequence for what it is without meaning (e.g. Milligan et al., 2007).

Readers vary considerably on the types of reading material they prefer. As expected, reading material that is associated with positive appraisals and expectations is more likely to be read on a regular basis (e.g., McGeown, Duncan, Griffiths, \& Stothard, 2015). Reading preference for one type of text over another may also depend upon receptive vocabulary and reading fluency. For example, reading fiction for recreational purposes and for literary experience is more likely when an individual can read fluently. In contrast, when an individual is less able to read fluently (e.g., Allington, 1984; Biemiller, 1977-1978; Cunningham \& Stanovich, 1997), they may be more likely to choose textual material other than books (e.g., comics). On the positive side, Hutchinson (1949) reported that reading comics increased poor readers' desire to read well even after school. However, on the negative side, Marshall and Roth (1978) reported that poor readers spent less time reading comics and constructing meanings therein compared to strong readers. They also reported that poor readers were more distracted by the pictures and paid less attention to the text for the abstraction of meaning than strong readers (Marshall \& Roth, 1978).

Reading often requires the reader to imagine specific social situations to which the written words refer, and presents the alternative perspectives of fictional and even non-fictional characters. Indeed, using a second order theoryof-mind task, Pelletier (2006) demonstrated that elementary school children, especially low-achieving readers, comprehended a written story better by using theory of mind skills. On this basis, it seems reasonable to propose that an individual's ability to coordinate social perspectives could be improved by reading and, in particular, that higher levels of SPT may be associated with more reading. In simple terms, the more RE an individual has, one might assume, the more perspectives that have been experienced.

The perspectives presented within reading material may also influence the relationship between SPT and reading. For example, Sato and Bergen (2013) reported that stories told from an internal perspective (e.g., the ego view) were associated with faster responses on SPT-related test items than when the same stories were told from an external perspective. However, when reading about another person or character, there is evidence that text describing the external (distal) perspective of that character (e.g., he sliced a tomato) rather than the internal (proximal) perspective (e.g., I sliced a tomato) facilitates better SPT during reading (Brunyé et al., 2009).

It may also be the case that exposure to different or unusual perspectives through reading specific types of material could influence SPT (i.e., SPT might be influenced by reading material that involves many examples of perspective taking). Indeed, the number of proximal and distal perspectives described in texts differs across types of reading material (e.g., fictional versus 
non-fictional, see Twenge, Campbell, \& Gentile, 2012). To assess RE in fifth graders, Cunningham and Stanovich (1997) used retrospective items to measure cumulative preferences and habits, and reported that first grade exposure to types of textual material predicted differences in the development of text comprehension in fifth grade reading.

Twenge et al. (2012) analyzed 766,513 books published in the United States between 1960 and 2008 (Google Books "ngram" database). Their analyses showed a decrease (effect size $d=1.52,-9 \%$ change) in the presentation of distal perspectives, but an increase ( $d=2.56,42 \%$ change) in the presentation of proximal perspectives. In parallel, Konrath, O'Brien, and Hsing (2011) reported reduced levels of SPT in American students between 1979 and 2000, with further deterioration since 2000. Taken together, these convergent findings highlight a potential relationship between inter-individual SPT differences and reading experience with divergent types of reading material, which has been the subject of little research interest. In addition, these combined findings draw attention to a potentially serious issue for future generations in terms of the potential decline in SPT. This concern prompted one of the current research questions -- what antecedents or predictors for the development of SPT may be applicable in learning and instruction?

Several studies have explored predictor variables of SPT, including those pertaining to reading (e.g., Barnes-Holmes, Barnes-Holmes, \& Murphy, 2004; Davlin et al., 2011; Schonert-Reichl et al., 2015; Van der Graaff et al., 2014). SPT and RE determinants identified in the literature thus far include: gender, vocabulary, reading fluency, type of reading material, and cultural and socioeconomic background. In studies of gender, for example, SPT has been shown to be stronger in females, relative to males, in children and adolescents (e.g., Van der Graaff et al., 2014).

\section{Aims and Hypotheses}

In this paper, we examine SPT and RE determinants that have already been identified in the literature. We present results on whether several factors determine later SPT in children and their RE with types of reading material (i.e., newspapers, journals, comics, books, and longer texts presented via computer or tablet). Finally, we describe the interrelations between SPT and $\mathrm{RE}$ in boys and girls over one year of school.

The aims of the current study were in part influenced by the research briefly reviewed above. Specifically, we aimed to: (1) replicate SPT determinants in school-age children (e.g., gender); (2) investigate the interrelations between SPT and RE over one year of school, considering the identified SPT and RE determinants; (3) analyze whether the relationship between SPT and gender is moderated by RE. According to Selman (1980), students at around the age of 10 are typically able to demonstrate 
reciprocal and third-person perspective coordination of interpersonal understanding. The research findings (Van der Graaff et al., 2014) reviewed above support the existence of SPT in this group; therefore, the data analyzed in this study were on students of this age. Theoretical approaches and findings from previous research (Barnes-Holmes et al., 2004) support the assumption that SPT in school-age children may be improved by reading, especially material that requires cognitive representation of a fictional character's view on a social situation. Conversely, children might report high RE when they have positively appraised immersion into fictional characters and when they report high SPT several months before. We tested our assumption of interrelations between SPT and RE by three hypotheses representing three steps: (1) SPT is determined by gender, cultural and socioeconomic background, receptive vocabulary, reading fluency, and RE on different types of reading activities of school-age children. (2) Reciprocal effects exist between students' SPT and RE over one year of school, even when controlling for cultural and socioeconomic background, receptive vocabulary, and reading fluency. (3) The relationship between SPT and gender is moderated by RE, again when controlling for the covariates mentioned in (2). To test the hypotheses, we used large-scale data that contained retrospective items for measuring SPT and RE. We expected to replicate the relationship between SPT and gender (Van der Graaff et al., 2014). We analyzed the interrelations between SPT and RE while considering gender by a simultaneous cross-lagged model on boys' and girls' data over time. We expected reciprocal relationships between SPT and RE over time. Students' high SPT-levels might be associated with a preference to immerse oneself in fiction and diverse social roles, thus, with more RE than those reporting low SPT. Furthermore, we expected that the relationship between SPT and gender known from previous research (e.g., Van der Graaff et al., 2014) is moderated by RE.

\section{Method}

\section{Data and Procedure}

The sample consisted of $N=2,105$ students ( $n=973$ female) from $k=127$ classes at 66 schools in Germany from a large-scale study on the development and quality of all-day schools (for a full description of sampling and procedure, see Fischer, Decristan, Theis, Sauerwein, \& Wolgast, 2017). The students attended the large-scale study with the consent of parents, the students themselves, school principals, and ministries of federal states. Ethical principles were considered while planning the study and the work was approved by an ethical committee. The students participated voluntarily and could withdraw from the study at any point of time. Anonymity was protected by IDs, blinded student names and blinded schools. In this sample, 
$n=637$ students $\left(M_{\text {age }}=10, S D_{\text {age }}=.46\right)$ attended a Gymnasium, the most academically-oriented type of secondary school in Germany; the other $n=1,468$ students $\left(M_{\text {age }}=10, S D_{\text {age }}=.61\right)$ attended secondary schools with a more vocational curriculum. The standardized tests and the questionnaire were computerized using study laptops in classes (i.e., each student used one laptop in a class with 10 or up to 25 students). The receptive knowledge of vocabulary (Weiß, 2006) and reading fluency (Auer, Gruber, Mayringer, \& Wimmer, 2011) of the students were tested. Self-report measures and information on the students' cultural and socioeconomic background (Adams \& Wu, 2002; Ganzeboom, De Graaf, \& Treiman, 1992) were gathered using a questionnaire. The students responded to the questionnaire at the beginning (T1), in the middle (T2), and at the end (T3) of fifth grade in September/ October 2013, January/February 2014, and June/July 2014, respectively. The summer break began after the study.

\section{Measures}

Social Perspective Taking. The students indicated on a 4-point scale (from $1=$ not true at all to $4=$ absolutely true) how they would act in various social situations involving reciprocal and self-reflective perspectives. Four items from the German version of the perspective taking subscale (Interpersonal Reactivity Index; Davis, 1980) were modified and one item was added. The subscale has been used in large-scale surveys (Fischer et al., 2017; Schonert-Reichl et al., 2015; Van der Graaff et al., 2014). The introduction, question, and five items were as follows: With the following questions, we would like to know a few things about you. How much do you agree with the following statements? a) I sometimes try to understand my friends better by imagining how things look from their perspective; b) I believe that there are two sides to every question and try to look at them both; c) Before criticizing somebody, I try to imagine how I would feel if I were in their place; d) I try to look at everybody's side of a disagreement before I make a decision; and e) I pay attention to how other people feel. Cronbach's $\alpha$ was good with $\alpha=.84$ in October 2013 (T1), $\alpha=.81$ in February 2014 (T2), and $\alpha=.86$ in July 2014 (T3). Item scale inter-correlations ranged from $r_{i t-i}=.56$ to $r^{i t-i}=.62$ and the postulated structure in a confirmatory factor analysis, including all measurement points, fit the data with robust maximum likelihood estimation. Fit indices were the root mean square error of approximation: RMSEA $=.046$, $\mathrm{CI}=[.040, .050]$, comparative fit index: $\mathrm{CFI}=.947$, and standardized root mean square residual: SRMR $=.031$. The students might comprehend the items differently across one year at school as boys might comprehend the items differently compared to girls. If so, the intercepts of the observed variables and structure of the measured factors would vary across one year of school and across gender; the means were not comparable in that case. Therefore, we conducted longitudinal multi-group invariance tests by the $\mathrm{R}$ package 
semTools (Pornprasertmanit, Miller, Schoemann, \& Rosseel, 2014). This item-scale assessed SPT scalar invariant over time and on the data of boys and girls (model fit indicated no significant model difference: $\chi^{2}=676.60-784.54$; fit indices suggested no significant differences and an acceptable fit: RMSEA $=.061-.064$; CFI $=.941-.931$; change of DELTA. $\mathrm{CFI}=.000-.010$, over time and across gender). Rutkowski and Svetina (2014) recommended to consider a difference in RMSEA $<.050$ and in CFI $<.020$ as acceptable fit across time points or groups in large-scale data. Thus, the factor structure, factor loadings and means of the proposed factor $S P T$ were comparable between the measurement points (over time) and between the data of boys and girls.

Reading Experience. Students at T1, T2, and T3 reported their experience with types of reading material by the question: How often do you read... (a) newspapers, (b) journals, (c) comics, (d) books, (e) longer texts at the computer/tablet? Students indicated on a 4-point scale (from $1=$ never to $4=$ almost ever) how often they read these types of reading material. Students used the full range from never to almost ever for their responses (see Table 1). Each item was considered as a manifest variable. Skewness was measured by adjusted Fisher-Pearson standardized moment coefficients, kurtosis by properties of symmetric distributions, and both were between -2 and 2 at T1, $\mathrm{T} 2$ and T3, supporting the assumption of normally distributed data (Joanes \& Gill, 1998; Revelle, 2015).

Predictor Variables. Receptive knowledge of vocabulary was assessed using the CFT 20-R (Weiß, 2006), a standardized inventory measuring comprehension of general and advanced German vocabulary as well as verbal processing capacity. Reading fluency was tested with the standardized Salzburger Lese-Screening 5-8 (Auer et al., 2011). Students read syntactically and grammatically simple sentences as quickly as possible and answered questions pertaining to the sentences. The children's gender was coded as $1=$ boys and $0=$ girls. Boys and girls performed comparably on both tests: receptive vocabulary $(\beta=-.01, p=.53$; standardized values) and reading fluency $(\beta=.00, p=1.00)$ at T1. Table 2 shows the correlations between the variables used. Receptive knowledge of vocabulary and reading fuency were moderately correlated.

We included cultural and socioeconomic background with the variables immigration status and socioeconomic status. We considered a student to have an immigration status if one of his/her parents or the child him-/herself was born outside Germany (this is in line with the criterion used in the Programme for International Student Assessment; Adams \& Wu, 2002; Entorf \& Minoiu, 2004) and if the predominant language spoken at home was not German. Students with an immigration background were coded as 1; those without were coded as 0 . 


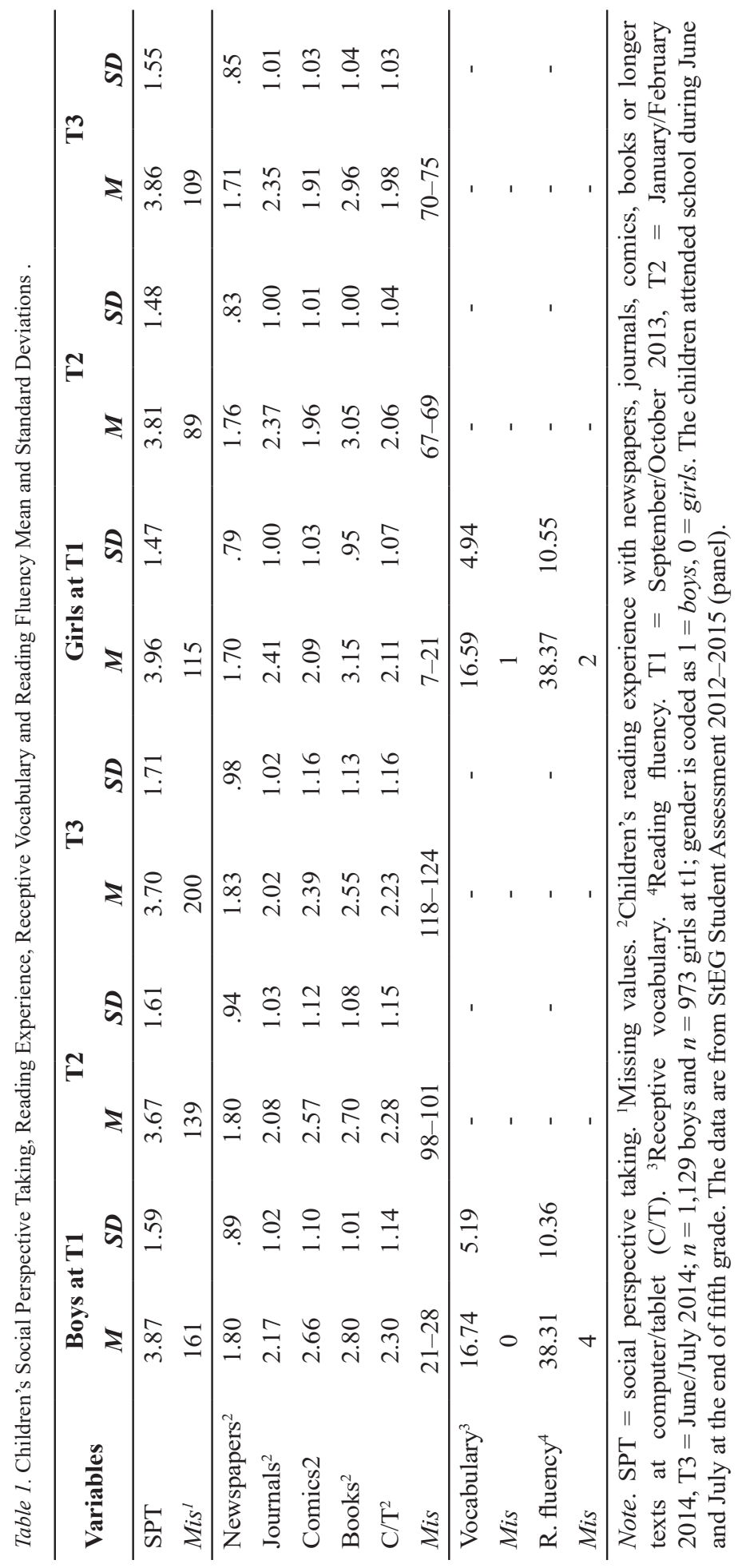


Table 2. Product-Moment Correlations among Variables at T1.

\begin{tabular}{|c|c|c|c|c|c|c|c|c|c|}
\hline Variable & SPT & $V$ & $R$ & SES & $N$ & $J$ & $C$ & $B$ & $C / T$ \\
\hline SPT & & $.09^{* *}$ & $.06^{*}$ & .03 & .03 & .05 & -.04 & $.10^{* *}$ & .01 \\
\hline $\begin{array}{l}\text { Receptive } \\
\text { vocabulary } \\
\text { (V) }\end{array}$ & $.16^{* * *}$ & & $.52^{* * *}$ & $.23^{* * * *}$ & $.07^{*}$ & $.14^{* * *}$ & $.08^{* * *}$ & $.15^{* * *}$ & $-.07^{*}$ \\
\hline $\begin{array}{l}\text { Reading } \\
\text { fluency } \\
\text { (R) }\end{array}$ & $.12^{* * * *}$ & $.55^{* * *}$ & & $.14^{* * *}$ & $.16^{* * *}$ & $.15^{* * *}$ & $.11^{* * *}$ & $.22^{* * * *}$ & .01 \\
\hline $\begin{array}{l}\text { Socioeconomic } \\
\text { status }\end{array}$ & .05 & $.31^{* * * *}$ & $.24^{* * *}$ & & .03 & $.09^{* *}$ & -.01 & $.15^{* * *}$ & $-.06^{*}$ \\
\hline $\begin{array}{l}\text { Newspapers }{ }^{1} \\
(\mathrm{~N})\end{array}$ & -.01 & $.09^{*}$ & $.16^{* * * *}$ & .05 & & $.48^{* * *}$ & $.13^{* * *}$ & $.17^{* * *}$ & $.18^{* * *}$ \\
\hline Journals $^{1}(\mathrm{~J})$ & -.02 & $.15^{* * * *}$ & $.19^{* * * *}$ & .05 & $.36^{* * * *}$ & & $.29^{* * *}$ & $.17^{* * *}$ & $.14^{* * * *}$ \\
\hline $\operatorname{Comics}^{1}(\mathrm{C})$ & -.02 & .01 & .01 & $-.08^{*}$ & $.12^{* * *}$ & $.22^{* * *}$ & & $.21^{* * *}$ & $.14^{* * * *}$ \\
\hline Books $^{1}$ (B) & $.07^{*}$ & $.22^{* * * *}$ & $.22^{* * * *}$ & $.13^{* * * *}$ & $.11^{* * * *}$ & $.07^{*}$ & $.08^{* * *}$ & & .05 \\
\hline $\mathrm{C} / \mathrm{T}^{1}$ & .01 & $-.16^{* * *}$ & $-.06^{*}$ & $-.06^{*}$ & $.14^{* * * *}$ & $.14^{* * *}$ & $.21^{* * * *}$ & $.08^{* *}$ & \\
\hline
\end{tabular}

Note. SPT $=$ social perspective taking. ${ }^{1}$ Children's RE with newspapers, journals, comics, books or longer texts at computer/tablet $(\mathrm{C} / \mathrm{T})$. Correlations of boys' data are depicted below the diagonal and of girls' data above the diagonal, ${ }^{* * *} \mathrm{p}<.001,{ }^{* *} \mathrm{p}<.01,{ }^{*} \mathrm{p}<.05$.

The SES of a student's family was assessed according to the Highest International Socio-Economic Index of Occupational Status (HISEI, Ganzeboom, De Graaf, Treiman, \& De Leeuw, 1992) and was determined by the highest status member, based on educational level and occupation, of the student's immediate family. The international standard classification of occupations ranges from the high rank "physical scientists, technical and related workers" (e.g., "aircraft and ships officers" or medical professionals) to the low rank "manual workers" (e.g., "street sweeper" or "road construction worker"; Ganzeboom et al., 1992, p. 33-55). The student's family $S E S$ varied by 77.40 points $(11.56=$ minimum, $88.96=$ maximum $)$. Values over 57.65 HISEI points were within the highest quartile and $57 \%$ of the students stemmed from that. Thus, the sample represents heterogeneous socioeconomic backgrounds but the majority of the students reported high socioeconomic backgrounds.

\section{Statistical Analyses}

We conducted statistical analyses with the R package lavaan (Rosseel, 2012) to test our hypotheses. First, we computed a latent regression model to identify the assumed determinants of SPT and RE. We specified SPT as a latent factor by the five SPT items as indicators with measurement error consideration. While SPT at T2 was an outcome variable, gender, cultural and socioeconomic background, receptive vocabulary, reading fluency, as well 
as the RE with types of reading material served as 10 predictor variables (and SPT at $\mathrm{T} 1$ as a covariate, see Table 3 ).

Children's RE with newspapers, journals, comics, books or longer texts via computer or tablet were considered as manifest variables in this statistical model. We also included the RE variables at T2 as five outcome variables in that model, including SPT at T1 as a predictor variable (and RE at T1 as covariates). Thereafter and to test the second hypothesis, we considered the result of the first model, i.e., only RE with newspapers or books due to the explained variance of these two variables in SPT (excluding RE with journals, comics or longer texts), in a latent autoregressive longitudinal model including cross-lagged paths (see Figure 1 for visualization). Therein, SPT assessed at T3 served as an outcome variable for RE assessed at T2, and in turn RE assessed at T3 served as an outcome variable for SPT assessed at T2. Three outcome variables were specified with variables at T3: SPT, RE on books and RE on newspapers. Predictive variables (PV) were SPT at T1 and T2 (PV1, PV2), RE on books at T1 and T2 (PV3 and PV4) and RE on newspapers at T1 and T2 (PV5 and PV6). Furthermore, we used a code to consider the data cluster structure 'classes at school' and a further code to simultaneously analyze boys' and girls' data (according to the third hypothesis). We compared the cross paths in nested models by the R package lmtest (Zeileis \& Hothorn, 2002). Multi-group analyses for testing differences between girls and boys were conducted.

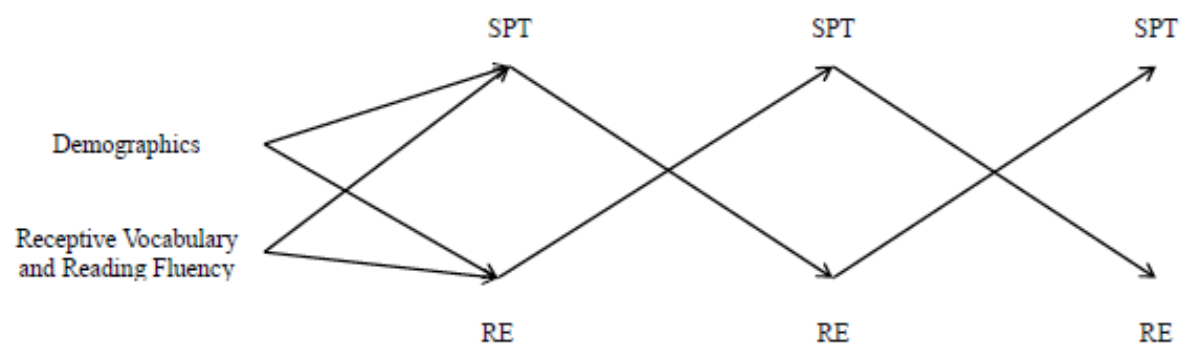

Figure 1. Heuristic model considered for all analyses, i.e., all statistical models based on that model. Demographics were students' gender, immigration background and SES. Reading skills included were receptive vocabulary and reading fluency.

Missing Values. Overall, missing values for SPT across the three measurement points ranged from $11 \%$ to $15 \%$, and Table 1 shows the numbers of missing values. The variable of SES consisted of $16 \%$ missing values of $N=2,105$ students (34 absentees, 300 not assignable to education or occupation). The missing values for the RE were below $6 \%$. Missing values for SES explained variance in SPT, R2 $=.002 ; F(1,1,887)=4.63, p=.03$, a result which supports the assumption about values missing at random (MAR; Rubin, 1996). Because of the missing values, we entered structural equations by the full information maximum likelihood (FIML) procedure provided in the R package lavaan (Rosseel, 2012). 


\section{Results}

\section{Longitudinal Determinants of Social Perspective Taking and Reading Experience}

The statistical modeling results for SPT and RE are presented in Table 3. Our first hypothesis was that SPT is determined by gender, cultural, and socioeconomic background, receptive vocabulary, reading fluency, and RE on different types of reading activities of school-age children. Subjective SPT (outcome variable 1) was positively determined by gender, and RE with books/newspapers, weighted least squares (WLS), fit indices: $\chi^{2}=600.521$, RMSEA $=.04, \mathrm{CI}=[.030, .036], \mathrm{CFI}=.96$, SRMR $=.042$. Boys reported significantly lower levels of SPT than girls at all three measurement points, $F(1,1,503)=36.96, p<.001$ (repeated measures GLM). Children reported lower levels of SPT when they recalled less RE than those who recalled more RE.

RE (outcome variable 2) was positively determined by gender, reading fluency (except for RE with comics), and SPT (except for RE with books). Children with a cultural and socioeconomic background external to Germany recalled significantly more RE with books or via computer than children with a German background. High levels of receptive vocabulary predicted more RE with books than low receptive vocabulary. Gender significantly determined later SPT in favor of girls.

\section{Longitudinal Associations between Social Perspective Taking and Reading Experience}

To test the second hypothesis of a reciprocal relationship between SPT and RE over one year of school, we analyzed associations by the latent autoregressive model including cross paths with the demographics, receptive vocabulary, and reading fluency as covariates at $\mathrm{T} 1$, as described above in Statistical Analyses (see Figure 1 for visualization). The results are depicted in Table 4. This model explained $47 \%$ of the variance in latent SPT at T3 and fit indices supported the assumed theoretical data structure (WLS, $\chi^{2}=377.195$; RMSEA $=.012$; C. I. $[.000, .019]$; CFI $=.99$; SRMR $=.038$ ). A Wald-test (Zeileis \& Hothorn, 2002) showed significant differences between the determination to the outcome variable SPT at T3, $\chi^{2}(144)=606.22$, and the outcome variable $\mathrm{RE}$ at $\mathrm{T} 3, \chi^{2}(144)=355.70, \chi^{2}$-difference $=250.52$, $p<.001$. Experience with reading newspapers at the beginning of fifth grade positively predicted only boys' SPT three months later at T2, whereas experience with reading books predicted girls' SPT in the same period of time. Subsequently, RE with newspapers positively predicted only girls' SPT three months later but not boys' SPT at T3. At the same period of time, a reciprocal path was significant (i.e., girls' SPT predicted their RE with newspapers at T3, see Table 4). 


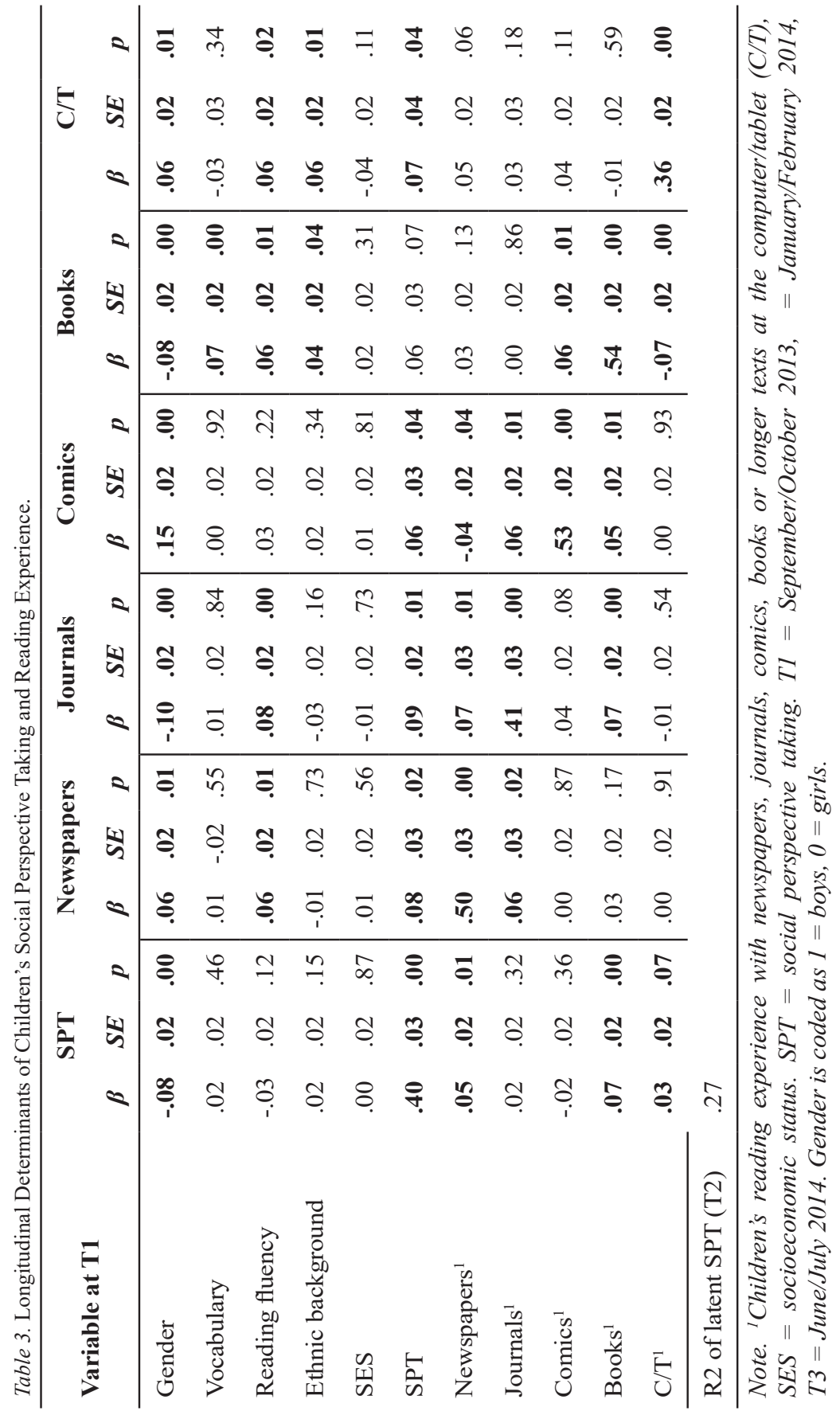




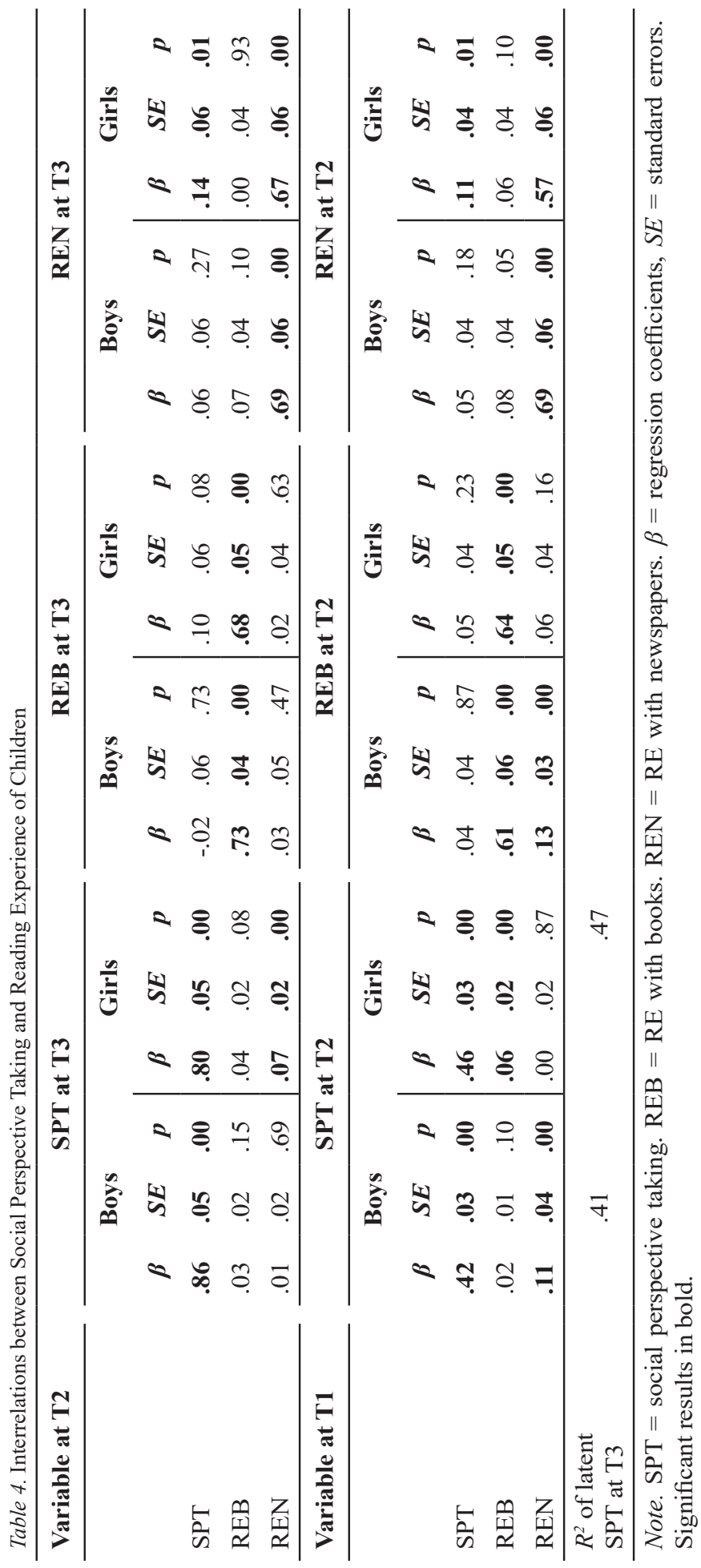


To draw conclusions about gender differences regarding our third hypothesis, a multi-group analysis was applied. We compared the SPT coefficients of boys and girls before assuming that there were any differences through RE. We compared boys' and girls' relationships between SPT and $\mathrm{RE}$, and found no significant difference over time; boys: $\chi^{2}(171)=191.23$, girls: $\chi^{2}(171)=185.97, \chi^{2}$-difference $=-5.26$.

\section{Discussion}

The aims of this longitudinal study were to test hypotheses about (1) SPT determinants and (2) the interrelations between fifth-grade students' SPT and $\mathrm{RE}$ with different types of reading material (assessed by retrospective items). A further aim (3) was to investigate whether associations between SPT and RE differed between boys and girls over time. We analyzed SPT by items (Davis, 1980) that represented dispositional SPT as a trait rather than a state, considering possible relevant factors (i.e., gender, cultural and socioeconomic background, receptive vocabulary, and reading fluency).

\section{Longitudinal Determinants of Social Perspective Taking and Reading Experience}

The result that high levels of receptive vocabulary predicted more RE with books than low receptive vocabulary partially supported hypothesis (1) regarding SPT determinants. Gender significantly determined later SPT in favor of girls, thus supporting our first hypothesis regarding SPT as determined by gender, and replicating previous research (e.g., Van der Graaff et al., 2014). SPT in this sample was determined by RE with books and newspapers, but not by cultural and socioeconomic background, receptive vocabulary, reading fluency, or RE with comics, journals or longer texts via computer or tablet. These findings corroborate previous research suggesting that different types of reading material were associated with different reader states or traits (e.g., Brunyé et al., 2009; Gore et al., 2010), and types of reading material differed significantly with regard to the proximal or distal perspectives described (Twenge et al., 2012).

The majority of students' SES was in the highest quartile and with a German background; SPT in students with diverse backgrounds might be influenced by SES and ethnicity. However, the results indicated more RE of children with a cultural background outside of Germany relative to children with a German background. This finding is unexpected, although one reason might be that children with an immigration background usually attend additional German courses in or out of school, and are exposed to different kinds of reading material as a result.

Students' SPT was not determined by receptive vocabulary or reading fluency and this result supports the assumption that SPT is associated more 
with trying to adopt the perspective of fictional characters than reading competency alone. Our results indicated that reading books and newspapers at around the age of 10 supported students' SPT-levels. The positive association between SPT and RE is consistent with results from other studies using different methods (Gore et al., 2010; Gouvain \& Munroe, 2014; Sato \& Bergen, 2013). Thus, reading about social situations described from various perspectives appears to influence students' levels of SPT.

\section{Longitudinal Associations between Social Perspective Taking and Reading Experience}

Our second hypothesis was inspired by an increasing amount of previous research suggesting associations between SPT and RE. Approaches to explain these associations were that reading specifies various social perspectives (Davlin et al., 2011; Fizke, Barthel, Peters, \& Rakoczy, 2014; Gehlbach, 2004; Selman, 1980) in mental representations (e.g., Buhl et al., 2009; O'Brien \& Albrecht, 1992). Specifically, proximal and distal perspectives are fundamental in fictional and non-fictional textual material (e.g., Twenge et al., 2012). Proximal perspectives described in a text activate an internal frame of reference (focus is directed at oneself) and distal perspectives activate an external frame of reference (focus is directed to others); textual material usually contains both. Shifting between various perspectives shows flexibility in responding relationally to the coordination of proximal and distal perspectives, as previous findings have demonstrated (e.g., Barnes-Holmes et al., 2004; Gore et al., 2010). Conversely, shifting between internal and external frames of reference might help to understand fictional characters described in texts. Children who understand the actions of fictional characters described in texts may read more often relative to those who understand less about the characters. Inspired by that theoretical approach, we assumed associations even between dispositional SPT and RE of school-age children in the current study. Our results indicated existing reciprocal relationships between SPT and RE regarding newspapers and books. Thus, the results from the educational field support the previous experimental research mentioned above (e.g., Davlin et al., 2011) and increase the validation degree of the used SPT items (Davis, 1980).

The previous experimental research on proximal and distal perspectives (e.g., Davlin et al., 2011) provides a conceptual explanation of why SPT and $\mathrm{RE}$ are associated, and our findings support the associations between SPT and RE over time. However, regarding our third hypothesis, (3) the reciprocal relationships between SPT and RE did not differ significantly between boys and girls over one year of school. Thus, this result did not support the third hypothesis. This highlights the relationship between SPT and RE for improving both SPT and RE. The relationship implies that SPT might be stimulated by reading activities, and those children with high SPT-levels (who like to 
imagine other social perspectives) might prefer reading activities than other activities. Furthermore, only boys' RE with newspapers increased the likelihood of their high SPT-levels a half year later. Boys preferred reading newspapers more than girls. Relevant factors for the different gender-specific connections of the reading preferences with SPT could be addressed in further research. We found empirical evidence for interrelations between SPT and $\mathrm{RE}$ across one year at school. This finding leads to a broader understanding of the relationship between SPT and RE.

\section{Limitations and Implications for Future Research}

Our statistical analyses were based on data from a longitudinal study in which self-reports and retrospective self-reports of children were used. Self-reported information provided by students on their SPT and retrospective RE might differ from that tested and accounted by researchers. Further research could explore associations among SPT, the educational content of reading materials, and the amount and type of previously read books. In the future, differences in variance of subjective assessments and objective assessments of SPT-levels could be compared for validation of both methods (self-reports versus tests) considering more specified types of reading material.

It would also be interesting to determine whether differences in the development of SPT were connected to the narrative voice in stories, and the proximal or distal perspectives described in the books that students read. Proximal and distal perspectives are described using pronouns that specify the relational perspectives to be adopted and how these relate to one another. In RFT, SPT is referred to as deictic relational frames and there are three such central features of one's perspective: interpersonal relations ( $I$ and $y o u$ ), spatial relations (here and there), and temporal relations (now and then). These relations interact with each other in important ways that allow an individual to acquire and appreciate his or her own perspective, as well as the perspectives of others, and even how these interact across contexts. Specifically, RFT argues that $I$ is always coordinated with here and now, while you is always anchored there and then (Foody et al., 2012; Weil, Hayes, \& Capurro, 2011).

Specifically, SPT experienced during reading is mediated by distal and proximal pronoun variations, as pronouns "explicitly identify the person performing an event" (Brunyé et al., 2009, p. 28). The number of pronouns in certain types of reading material could be counted systematically to figure out if comics involve less perspectives and pronouns than novels or other books, and thus children would benefit more from reading more "books." Additional variables (e.g., stress levels of students and students' schedules) that might impact subjective assessments and objective assessments of SPT could also be taken into account. To conceptualize SPT in a broader sense, we suggest use of the term "perspective coordination" as used by Selman 
(1980). This implies that students acquire a coordination of different perspectives that is more or less similar to their own, rather than an unreflective "taking or applying another one's view." An individual cannot actually take the social perspective of another person. For example, when an individual empathizes with another, s/he may understand what the other person feels (cognitive dimension of empathy), but cannot directly experience the other person's feelings (emotional dimension of empathy; Chambers \& Davis, 2012; Davis, 1980; Mischo, 2005; Selman, 1980). Interestingly, Schonert-Reichl et al. (2015) used Davis' measure and reported higher subjective levels of SPT in fourth- and fifth-graders after mindfulness training, relative to controls.

Assessments that measure the ability and motivation to coordinate social perspectives, especially in classrooms, would be helpful for the development of useful tools to practice imagining situations involving multiple target individuals. That is relevant for social behavior inside and outside school. In future research, this might be investigated directly using an experimental design in which students read specific texts and then complete social perspective coordination tasks. Following previous suggestions (Gehlbach, 2004; Schonert-Reichl et al., 2015) that SPT should be taught in schools, our study has shown the potential for both boys and girls to support their SPT by reading at school. Accordingly, teachers might support children's SPT at school by reading fictional stories and triggering imagination of the fictional characters. For example, children might read about a fictional character and simulate the character in short roleplays. SPT ultimately has wide implications for communication processes and social behavior in general (e.g., Epley \& Caruso, 2008). When social learning interventions at schools involve children's shifting between first- and third-person perspectives, it might not only influence students' well-being, but also improve academic outcomes.

\section{Acknowledgement}

The longitudinal data used in this study were collected for part of a study funded by the German Federal Ministry of Education and Research (StEG-S funding number: 01GTS0311A und B).

\section{References}

Adams, R., \& Wu, M. (2002). PISA 2000 Technical Report. Paris: Organisation for Economic Co-operation and Development (OECD). Retrieved from https://www.oecd.org/pisa/pisaproducts/33688233.pdf

Allington, R. L. (1984). Content coverage and contextual reading in reading groups. Journal of Reading Behavior, 16, 85-96. doi:10.1080/10862968 409547506 
Atkins, D., Uskul, A. K., \& Cooper, N. R. (2016). Culture shapes empathic responses to physical and social pain. Emotion, 16, 587-601. doi:10.1037/ emo0000162

Auer, M., Gruber, G., Mayringer, H., \& Wimmer, H. (2011). Salzburger Lese-Screening für die Klassenstufen 5-8 (SLS 5-8) [Salzburg reading assessment for fifth to eight grade students]. Bern: Hans Huber.

Barnes-Holmes, Y., McHugh, L., \& Barnes-Holmes, D. (2004). Perspective taking and theory of mind: A relational frame account. The Behavior Analyst Today, 5, 15-25. doi:10.1037/h0100133

Baron-Cohen, S., Bowen, D. C., Holt, R. J., Allison, C., Auyeung, B., Lombardo, M. V. et al. (2015). The "reading the mind in the eyes" test: Complete absence of typical sex difference in $\sim 400$ men and women with Autism. PLoS ONE, 10, e0136521. doi:10.1371/journal.pone.0136521

Baron-Cohen, S., Tager-Flusberg, H., \& Lombardo, M. V. (2013). Understanding other minds: Perspectives from developmental social neuroscience. Oxford: Oxford University Press.

Biemiller, A. (1977-1978). Relationships between oral reading rates for letters, words, and simple text in the development of reading achievement. Reading Research Quarterly, 13, 223-253. doi:10.2307/747307

Blakemore, S. J., \& Choudhury, S. (2006). Development of the adolescent brain: implications for executive function and social cognition. Journal of Child Psychology and Psychiatry, 47, 296-312. doi: 10.1111/j.14697610.2006.01611.x

Bloom, P., \& German, T. P. (2000). Two reasons to abandon the false belief task as a test of theory of mind. Cognition, 77, B25-B31. doi:10.1016/ S0010-0277(00)00096-2

Britt, M., Goldman, S., \& Rouet, J. (Eds.). (2012). Reading: From words to multiple texts. New York, NY: Routledge.

Brunyé, T. T., Ditman, T., Mahoney, C. R., Augustyn, J. S., \& Taylor, H. A. (2009). When you and I share perspectives. Pronouns modulate perspective taking during narrative comprehension. Psychological Science, 20, 27-32. doi:10.1111/j.1467-9280.2008.02249.x

Buhl, H. M., Möller, F., Oebser, M., Stein, F., \& Noack, P. (2009). Zusammenhänge zwischen der Fähigkeit zur Perspektivenübernahme und dem Textverstehen im Vor- und Grundschulalter [Associations between perspective-taking skill and text comprehension of pre-school and elementary-school students] . Diskurs Kindheits- und Jugendforschung, 1, 75-90.

Chambers, J. R., \& Davis, M. H. (2012). The role of the self in perspective taking and empathy: Ease of self-simulation as a heuristic for inferring empathic feelings. Social Cognition, 30, 153-180. doi:10.1521/ soco.2012.30.2.153 
Cunningham, A. E., \& Stanovich, K. E. (1997). Early reading acquisition and its relation to RE and ability 10 years later. Developmental Psychology, 33, 934-945. doi:10.1037//0012-1649.33.6.934

Davis, M. H. (1980). A multidimensional approach to individual differences in empathy. JSAS Catalog of Selected Documents in Psychology, 10, 85-94.

Davlin, N. L., Rehfeldt, R. A., \& Lovett, S. (2011). A relational frame theory approach to understanding perspective taking using children's stories in typically developing children. European Journal of Behavior Analysis, 12, 403-430.

Entorf, H., \& Minoiu, N. (2004). What a difference immigration law makes: PISA results, migration background and social mobility in Europe and traditional countries of immigration. ZEW Discussion Paper No. 04-17. Retrieved from http://www.zew.de/de/publikationen/2096

Epley, N., \& Caruso, E. M. (2008). Perspective taking: Misstepping into others' shoes. In K. D. Markman, W. M. Klein, \& J. A. Suhr (Eds.), Handbook of imagination and mental simulation (pp. 297-311). New York, NY: Psychology Press.

Erle, T., \& Topolinski, S. (2015). Spatial and empathic perspective-taking correlate on a dispositional level. Social Cognition, 33, 187-210. doi:10.1521/soco.2015.33.3.187

Fischer, N., Decristan, J., Theis, D., Sauerwein, M., \& Wolgast, A. (2017). StEG-S-Skalen-dokumentation [StEG-S-scales documentation]. Deutsches Institut für Internationale Pädagogische Forschung (DIPF). https://doi. org/10.7477/199:180:1

Fizke, E., Barthel, D., Peters, T., \& Rakoczy, H. (2014). Executive function plays a role in coordinating different perspectives, particularly when one's own perspective is involved. Cognition, 130, 315-334. doi:10.1016/j. cognition.2013.11.017

Foody, M., Barnes-Holmes, Y., \& Barnes-Holmes, D. (2012). The role of self in acceptance and commitment therapy (ACT). In L. McHugh, \& I. Stewart (Eds.), The self and perspective taking: research and applications (pp. 126142). Oakland, CA: New Harbinger.

Galinsky, A. D., Ku, G., \& Wang, C. S. (2005). Perspective taking: Fostering social bonds and facilitating social coordination. Group Processes and Intergroup Relations, 8, 109-125. doi:10.1177/1368430205051060

Ganzeboom, H. B. G., De Graaf, P. M., \& Treiman, D. J. (1992). A standard international socio-economic index of occupational status. Social Science Research, 21, 1-56. doi:10.1016/0049-089X(92)90017-B

Gardner, W. L., Gabriel, S., \& Lee, A. Y. (1999). "I" value freedom, but "we" value relationships: Self-construal priming mirrors cultural differences in judgment. Psychological Science, 10, 321-326. doi:10.1111/14679280.00162 
Gauvain, M., \& Munroe, R. L. (2014). Development of perspective taking in relation to age, education, and the presence of community features associated with industrialization: A four-culture study. Cross-Cultural Research, 48, 32-44. doi:10.1177/1069397113502164

Gehlbach, H. (2004). A new perspective on perspective taking: A multidimensional approach to conceptualizing an aptitude. Educational Psychology Review, 16, 207-234. doi:10.1023/B:EDPR. 0000034021.12899 .11

Gore, N., Barnes-Holmes, Y., \& Murphy, G. (2010). The relationship between intellectual functioning and relational perspective taking. International Journal of Psychology and Psychological Therapy, 10, 1-17. Retrieved from http://www.ijpsy.com/volumen10/num1/247/the-relationship-betweenintellectual-functioning-EN.pdf

Hutchinson, K. H. (1949). An experiment in the use of comics as instructional material. The Journal of Educational Sociology, 23, 236-245. Retrieved from http://www.jstor.org/stable/2264559

Joanes, D. N., \& Gill, C. A. (1998). Comparing measures of sample skewness and kurtosis. The Statistician, 47, 183-189. doi:10.1111/1467-9884.00122

Konrath, S., O'Brien, E., \& Hsing, C. (2011). Changes in dispositional empathy in American college students over time: A meta-analysis. Personality and Social Psychology Review, 15, 180-198. doi:10.1177/1088868310377395

Lillard A. (1998). Ethopsychologies: Cultural variations in theories of mind? Psychological Bulletin, 123, 3-32. doi:10.1037/0033-2909.123.1.3

Lohmann, H., \& Tomasello, M. (2003). The role of language in the development of false belief understanding: A training study. Child Development, 74, 1130-1144. doi:10.1111/1467-8624.00597

Marshall, A., \& Roth, G. (1978). Pupils' use of time while reading comics and books. American Educational Research in Journalism, 15, 201-216. doi:10.3102/00028312015002201

McGeown, Sarah P., Duncan, L. G., Griffiths, Y. M., \& Stothard, S. E. (2015). Exploring the relationship between adolescent's reading skills, reading motivation and reading habits. Reading and writing, 28, 545-569. doi:10.1007/s11145-014-9537-9

Milligan, K., Astington, J. W., \& Dack, L. A. (2007). Language and theory of mind: Meta-analysis of the relation between language ability and false-belief understanding. Child Development, 2, 622-646. doi:10.1111/ j.1467-8624.2007.01018.x

Mischo, C. (2005). Promoting perspective coordination by dilemma discussion. The effectiveness of classroom group discussion on interpersonal negotiation strategies of 12-year-old students. Social Psychology of Education, 8, 41-63. doi:10.1007/s11218-004-1884-y 
Mullis, I. V. S., Martin, M. O., \& Sainsbury, M. (2015). PIRLS 2016 reading framework. In I. V. S. Mullis, \& M. O. Martin (Eds.), PIRLS 2016 assessment framework (2nd ed., p. 11-29). Chestnut Hill, MA: TIMSS and PIRLS International Study Center. Retrieved from timss.bc.edu/ pirls2016/downloads/P16_FW_Chap1.pdf

Nieding, G., \& Ohler, P. (1999). Der Einfluss von Protagonisten-Zielstrukturen auf räumliche mentale Modelle beim narrativen Textverstehen von Kindern [Influences of protagonist-goal-structures on spatial mental models while narrative text comprehension]. Sprache \& Kognition, 18, 146-158. doi:10.1024//0253-4533.18.34.146

O'Brien, E. J., \& Albrecht, J. E. (1992). Comprehension strategies in the development of a mental model. Journal of Experimental Psychology: Learning, Memory, and Cognition, 18, 777-784. doi:10.1037/0278-7393. 18.4.777

Pelletier, J. (2006). Relations among theory of mind, metacognitive language, reading skills and story comprehension in L1 and L2 learners. In A. Antonietti, O. Sempio-Liverta, \& A. Marchetti (Eds.), Theory of mind and language in developmental contexts (pp. 77-92). New York, NY: Springer.

Piaget, J. (1977). Intellectual evolution from adolescence to adulthood. In P. Wason \& P. Johnson-Laird (Eds.), Thinking (pp. 158-165). Cambridge: Cambridge University.

Pornprasertmanit, S., Miller, P., Schoemann, A., \& Rosseel, Y. (2014). semTools: Useful tools for structural equation modeling. R package version 0.4-6. Retrieved from http://CRAN.R-project.org/package=semTools

Revelle, W. (2015). psych: Procedures for Personality and Psychological Research. Northwestern University, Evanston, Illinois, USA. Retrieved from http://CRAN.R-project.org/package=psych Version $=1.5 .8$.

Rosseel, Y. (2012). lavaan: An R package for structural equation modeling. Journal of Statistical Software, 48, 1-36. Retrieved from http://www. jstatsoft.org/v48/i02/

Rubin, D. B. (1996). Multiple imputation after 18+ years. Journal of the American Statistical Association, 91, 473-489. doi:10.2307/2291635

Sato, M., \& Bergen, B. (2013). The case of the missing pronouns: Does mentally simulated perspective play a functional role in the comprehension of person? Cognition, 127, 361-374. doi:10.1016/j.cognition.2013.02.004

Schneider, W. (2015). Memory development from early childhood through emerging adulthood. Heidelberg: Springer. 
Schonert-Reichl, K. A., Oberle, E., Steward, Lawlor, M., Abbott, D., Thomson, K., Oberlander, T., \& Diamond, A. (2015). Enhancing cognitive and social-emotional development through a simple-to-administer mindfulness-based program for elementary school children: A randomized controlled trial. Developmental Psychology, 51, 52-66. doi:10.1037/a0038454

Selman, R. L. (1980). The growth of interpersonal understanding Developmental and clinical analyses. New York, NY: Academic Press.

Smith, R. L., \& Rose, A. J. (2011). The "Cost of Caring" in youths' friendships: Considering associations among social perspective taking, co-rumination, and empathetic distress. Developmental Psychology, 47, 1792-1803. doi:10.1037/a0025309

Spinner, K. (1989). Fremdverstehen und historisches Verstehen als Ergebnis kognitiver Entwicklung [Alien understanding and historical understanding resulting from cognitive development]. Der Deutschunterricht, 4, 19-23.

Twenge, J. M., Campbell, W. K., \& Gentile, B. (2012). Changes in pronoun use in American books and the rise of individualism, 1960-2008. Journal of Cross-Cultural Psychology, 44, 406-415. doi: 10.1177/ 0022022112455100

Van der Graaff, J., Branje, S., De Wied, M., Hawk, S., Van Lier, P., \& Meeus, W. (2014). Perspective taking and empathic concern in adolescence: Gender differences in developmental changes. Developmental Psychology, 50, 881-888. doi:10.1037/a0034325

Varnum, M. E. W., Shi, Z., Chen, A., Qiu, J., \& Han, S. (2014). When "your" reward is the same as "my" reward: Self-construal priming shifts neural responses to own vs. friend's rewards. NeuroImage, 87, 164-169. doi:10.1016/j.neuroimage.2013.10.042

Weil, T. M., Hayes, S. C., \& Capurro, P. (2011). Establishing a deictic relational repertoire in young children. The Psychological Record, 61, 371-390. doi:10.1007/BF03395767

Weiß, R. H. (2006). Wortschatztest und Zahlenfolgentest - Revision Ergänzungstests zum CFT 20-R (WS/ZF-R) [Vocabulary and number sequencing test - revised in addition to CFT 20-R]. Göttingen: Hogrefe.

Zeileis, A., \& Hothorn, T. (2002). Diagnostic checking in regression relationships. R News, 2, 7-10. Retrieved from http://CRAN.R-project.org/doc/Rnews/ 